\title{
Cambios en la patria potestad y en especial de su ejercicio conjunto
}

\author{
Marcela Acuña San Martín ${ }^{1 *}$
}

\section{RESUMEN}

Se analiza la actual estructura de titularidad en el ejercicio de la patria potestad establecida por la Ley 20.680 de 2013. Ello se hace a partir de las nuevas reglas establecidas en los artículos 244 y 245 del Código Civil y de los cambios en la atribución y modalidades de cuidado personal de los hijos. Se profundiza especialmente en la forma de ejercicio conjunto de la patria potestad y su real alcance.

Patria potestad - cuidado personal - ejercicio conjunto.

\section{Changes in parental authority and especially its joint exercise}

\begin{abstract}
The current ownership structure in the parental authority exercise, established by Law 20.680 of 2013, is analyzed. The aforementioned is made starting from the new rules laid down in articles 244 y 245 of the Civil Code, and the changes on the children personal care attribution and modalities. It goes deep on the parental authority joint exercise way and its real scope.
\end{abstract}

Parental authority - child custody - joint exercise

* Universidad de Talca.

${ }^{1}$ Abogada, Licenciada en Ciencias Jurídicas de la Universidad Austral de Chile y Doctora en Derecho de la Universidad de Zaragoza (España); ejerce docencia en la Universidad de Talca, mail: acunasm@utalca.cl.

Abreviaturas empleadas: art. artículo; arts. artículos; CC Código Civil; CDN Convención de derechos del niño; inc. inciso; LMC Ley de Matrimonio Civil.

Artículo recibido el 3 de mayo de 2014 y aceptado para su publicación por el Comité Editorial el 27 de marzo de 2015. 


\section{INTRODUCCIÓN}

$\mathrm{L}$ a modificación llevada a cabo por la Ley 20.680 de 2013 en el Código Civil y otros cuerpos legales con el objeto de proteger la integridad del menor en caso de que sus padres vivan separados, ha generado gran atención de especialistas, académicos y litigantes principalmente en torno al sistema de cuidado personal compartido que posibilita y al principio de corresponsabilidad parental que consagra. Sin perjuicio de la innegable relevancia de ambos temas, la ley imprime cambios de cierta significación también en otras instituciones jurídicas como es el caso de la patria potestad.

No es despreciable el número de incidencias en la relación cotidiana entre los padres, entre padres e hijos o respecto de terceros que se vinculan con actuaciones o decisiones que inciden en lo que nuestro Derecho denomina patria potestad. A su turno, algunas de estas interesantes cuestiones han llegado al conocimiento de los tribunales. Este trabajo tiene el doble propósito de realizar, por un lado, una propuesta de ordenación sistemática de la actual estructura de titularidad en la atribución del ejercicio de la patria potestad; y, por otro, delimitar las hipótesis y principales consecuencias prácticas de la actuación conjunta en el ejercicio de aquella potestad. Para ello en la primera parte se revisa la regulación de la estructura de titularidad de la patria potestad antes y después de la Ley 20.680, lo que se hace observando su relación con el cuidado personal; en la segunda parte se desarrolla un estudio más detenido de la modalidad de ejercicio conjunto precisando su real alcance, el que, como se verá, resulta más restringido de lo que aparentan las nuevas disposiciones. Se termina con algunas reflexiones generales referente a estas materias.

\section{Primera parte}

\section{Aproximación al binomio cuidado personal-patria potestad}

En la generalidad de los ordenamientos jurídicos la patria potestad se concibe como la función tuitiva que corresponde a los padres respecto de sus hijos, función que se despliega en el ámbito personal y patrimonial ${ }^{2}$. La patria potestad aparece como un efecto legal y propio de la relación paterno-filial ${ }^{3}$; se configura como una función tuitiva general, comprensiva tanto de la esfera patrimonial como de la esfera personal del menor;

\footnotetext{
${ }^{2}$ Así por ejemplo el art. 264 del CC argentino que señala: La patria potestad es el conjunto de deberes y derechos que corresponden a los padres sobre las personas y bienes de los hijos, para su protección y formación integral, desde la concepción de estos y mientras sean menores de edad y no se hayan emancipado, o el art. 413 del CC mexicano que expresa: La patria potestad se ejerce sobre la persona y los bienes de los hijos. El art. 154 del CC español, por su parte, prescribe La patria potestad se ejercerá siempre en beneficio de los hijos, de acuerdo con su personalidad, y con respeto a su integridad física y psicológica y que comprende los siguientes deberes y facultades: $1^{\circ}$ Velar por ellos, tenerlos en su compañia, alimentarlos, educarlos y procurarles una formación integral y $2^{\circ}$ Representarlos $y$ administrar sus bienes.

${ }^{3}$ Díez-Picazo, L. y Gullón, A., Sistema de Derecho Civil, vol. IV, 10ª edición, Tecnos, Madrid, 2006, p. 270.
} 
se la concibe como un sistema de protección, cuidado, asistencia física, moral y educación y un medio de suplir la incapacidad del hijo no emancipado ${ }^{4}$ y de los mayores de edad incapacitados; se habla también de una función social al servicio del hijo y de ejercicio obligatorio para quien la ostenta ${ }^{5}$. Por lo mismo, no se alude a un derecho subjetivo del patriarca familiar o de ambos progenitores, sino a una potestad en sentido técnico. En España por ejemplo, la patria potestad es una institución básica del orden social-familiar, cuyo ejercicio se encuentra siempre funcionalizado, pues se ejerce en beneficio del hijo ${ }^{6}$.

En nuestro medio, en cambio, la patria potestad por definición es una institución relativa solo a los bienes: La patria potestad es el conjunto de derechos y deberes que corresponden al padre o a la madre sobre los bienes de sus hijos no emancipados y se ejerce también sobre los derechos eventuales del bijo que está por nacer (art. 243 del CC) ${ }^{7}$. La doctrina en general asume esta dicotomía distinguiendo entre autoridad paterna y patria potestad ${ }^{8}$; la primera referida a la persona de los hijos, la segunda relativa a los bienes de estos, sin perjuicio de hacer presente los inconvenientes de tal división ${ }^{9}$. Esta dualidad se mantiene desde Bello hasta nuestros días, aunque con una importante evolución en la titularidad y ejercicio de los derechos y deberes ${ }^{10}$.

No obstante que la autoridad paterna -mejor llamada autoridad parental- tiene un contenido personal más amplio, el cuidado personal de los hijos es su principal concreción. El Código Civil regula por un lado el cuidado personal, que corresponde

\footnotetext{
${ }^{4}$ Pérez Álvarez, M., en Martínez de Aguirre, C. (coord.), Curso de Derecho Civil (IV), Derecho de Familia, $3^{\text {a }}$ edición, Colex, Madrid, 2011, p. 346.

${ }^{5}$ Menéndez, J., en Domínguez, A. (coord.), Comentarios al Código Civil, Lex Nova, Valladolid, 2010, p. 272. De la naturaleza funcional de la patria potestad se hace derivar por ejemplo la circunstancia de ser indisponible la titularidad, no así su ejercicio: Roca, E., en Amoros, M. (coord.), Comentarios a las reformas del Derecho de Familia, vol. I, Tecnos, Madrid, 1984, p. 552. Con todo, la idea de función social no es compartida por toda la doctrina al estimarse que se trata de una configuración exagerada y confusa por imprecisa: Lasarte, C., Principios de Derecho Civil. Derecho de Familia, tomo VI, 7 a edición, Marcial Pons, Madrid, 2008, p. 332.

${ }^{6}$ Díez-Picazo, L. y Gullón, A., Sistema de Derecho Civil, vol. IV, 10ª edición, Tecnos, Madrid, 2006, p. 271.

${ }^{7}$ Corral informa que Bello adoptó en esto la regulación del Code que establecía una familia marcadamente jerarquizada, lo que explica el poder del padre sobre los hijos nacidos en matrimonio además de la hoy derogada potestad marital: Corral, H., "La familia en los 150 años del Código Civil Chileno", en Revista Chilena de Derecho, vol. 32, No 3, 2005, p. 430.

${ }^{8}$ Gómez de la Torre, M., Sistema filiativo chileno, Editorial Jurídica de Chile, Santiago, 2007, p. 131; Troncoso, H., Derecho de Familia, Lexis Nexis, Santiago, 2007, p. 313. Abeliuk califica como situación única que nuestra legislación hubiera desglosado de la patria potestad el cuidado personal de los hijos, cuya finalidad obedeció simplemente a no otorgar a la madre la administración de bienes: Abeliuk, R., La filiación y sus efectos, tomo I, Editorial Jurídica de Chile, Santiago, 2003, p. 23 y 313. Una posición aislada distinta sostiene que la patria potestad es una función tuitiva que se despliega en el ámbito personal y patrimonial, aunque para poder llegar a tal afirmación tenga que partir reconociendo que la denominación de patria potestad que utiliza lo es en un sentido genérico y no en el sentido estricto y clásico del Código Civil: Rodríguez, M. S., "Una relectura de la patria potestad como función tuitiva sobre la persona y bienes de los hijos", en Revista Ius et Praxis, año 16, $\mathrm{N}^{\circ} 1,2010$, p. 56.

9 Álvarez, C., "Derechos y obligaciones entre padres e hijos, en particular de la autoridad paterna", en Revista de Derecho Universidad de Concepción, No 204, año LXVI, 1998, p. 63.

${ }^{10} \mathrm{Al}$ respecto se puede revisar Rodríguez, M. S. "Una relectura de la patria potestad como función tuitiva sobre la persona y bienes de los hijos", en Revista Ius et Praxis, año 16, No 1, 2010, pp. 55 a 84.
} 
básicamente a las atenciones diarias (art. 224 y 225 CC), y por otro, la patria potestad con el significado legal ya apuntado (art. 243 y ss. CC) y que -a diferencia del cuidado personal-se encuentra siempre radicada exclusivamente en los progenitores ${ }^{11}$.

Durante la tramitación de la Ley 20.680 se planteó la necesidad de crear una figura omnicomprensiva de los derechos y deberes parentales tanto patrimoniales como extrapatrimoniales -a la luz de los principios que inspiraban el proyecto- ${ }^{12}$, pero, como comenta algún autor, esta tarea unificadora y sistematizadora fue desechada por extralimitar la idea matriz del mismo ${ }^{13}$. Por tanto se mantiene en nuestro Código Civil el tratamiento separado de los aspectos personales y patrimoniales que derivan de la filiación.

\section{Estructura de asignación de derechos y facultades derivados de la filiación}

Si bien en nuestro país se presenta una disociación entre los aspectos personales y los patrimoniales de la relación paterno-filial, la misma es parcial, pues existe una dependencia o estrecha vinculación entre ambos.

\subsection{Situación anterior a la Ley 20.680 de 21 de junio de 2013}

En materia de cuidado personal si los padres viven juntos disponía el inc. primero del art. 224 CC: Toca de consuno a los padres, o al padre o madre sobreviviente, el cuidado personal de la crianza y educación de sus hijos, no admitiendo el legislador otra posibilidad de cuidado personal. Para los casos en que los padres viven separados el art. 225 CC establecía tres reglas de atribución del cuidado personal, a saber: Si los padres viven separados, a la madre toca el cuidado personal de los hijos (atribución legal del inc. $1^{\circ}$ del art. 225 CC); No obstante, mediante escritura pública, o acta extendida ante cualquier oficial del Registro Civil, subinscrita al margen de la inscripción de nacimiento del bijo dentro de los treinta dias siguientes a su otorgamiento, ambos padres, actuando de común acuerdo, podrán determinar que el cuidado personal de uno o más hijos corresponda al padre. Este acuerdo podrá revocarse, cumpliendo las mismas solemnidades (atribución convencional del inc. $2^{\circ}$ del art. 225 CC); y en todo caso, cuando el interés del bijo lo haga indispensable, sea por maltrato, descuido u otra causa calificada, el juez podrá entregar su cuidado personal al otro de los padres. Pero no podrá confiar el cuidado personal al padre o madre que no bubiese contribuido a la mantención del bijo

${ }^{11}$ Corte Suprema, 5 de mayo de 2013, en autos rol 26-2013, en www.microjuris.com, cita MJJ34609.

12 Así lo plantearon la profesora Andrea Muñoz y el profesor Mauricio Tapia en Informe en segundo trámite constitucional, de 22 de junio de 2012. El proyecto de la Ley 19.585 propuso un estatuto jurídico único de la relación filial, sin embargo en su discusión se dejó constancia de la conveniencia de utilizar criterios y normas particulares para los aspectos pecuniarios y los de orden personal, considerando que tanto doctrina como jurisprudencia habían funcionado hasta la fecha satisfactoriamente. La doctrina desde entonces ha reclamado como reforma legal pendiente la unificación del aspecto personal y patrimonial, así: Schmidt, C., "De las relaciones parentales conforme al nuevo estatuto filiativo", en Schmidt, C. y Martinic, M. D. (directoras) Instituciones de derecho de familia, LexisNexis, Santiago, 2004, p. 35 y ss.

${ }^{13}$ Lathrop, F., "Comentarios a la reforma al código civil en materia de efectos de la filiación", en $L a$ Semana Jurídica, año II, $\mathrm{N}^{\circ}$ 58, LegalPublishing, 2013, p. 7. 
mientras estuvo bajo el cuidado del otro padre, pudiendo hacerlo (atribución judicial del inc. $3^{\circ}$ del art. 225 CC). En todas estas hipótesis, el cuidado personal siempre quedaba radicado individualmente en uno de los padres.

Pese a las posibilidades que reconocían los inc. $2^{\circ}$ y $3^{\circ}$ del art. 225 CC, en la realidad aplicativa, en la gran mayoría de los casos, principalmente por la ausencia de acuerdo, la madre ejercía el cuidado personal de modo exclusivo respecto de todos los hijos menores, cualquiera fuera su sexo o edad ${ }^{14}$.

En materia de patria potestad, si los padres vivían juntos el art. 244 CC. establecía el ejercicio por el padre o la madre o ambos conjuntamente, según convengan en acuerdo solemne. A falta de acuerdo, al padre toca el ejercicio de la patria potestad. En todo caso, cuando el interés del hijo lo haga indispensable, a petición de uno de los padres, el juez podrá confiar el ejercicio de la patria potestad al padre o madre que carecía de él, o radicarlo en uno solo de los padres, si la ejercieren conjuntamente. Aun viviendo juntos los padres el legislador daba preeminencia al ejercicio individual y hasta lo imponía; solo con carácter excepcional y por acuerdo solemne era posible el ejercicio conjunto.

Resultaba extraña la variación de criterio en la solución legal para reglar los aspectos personales y patrimoniales que dicen relación con los hijos cuando los padres viven juntos, pues mientras el cuidado personal debía ser asumido - sin excepción- de consuno por ambos padres, siguiendo el orden normal de la dinámica familiar habitual, la patria potestad por ley le correspondía al padre, con lo que, la propia ley generaba una fisura normativa en la asunción de las funciones parentales que solo encontraba explicación en la lógica original del Código consistente en limitar la administración materna de bienes.

Si los padres vivían separados el art. 245 CC disponía que la patria potestad sería ejercida por aquel que tenga a su cargo el cuidado personal del bijo, de conformidad al artículo 225. Esta atribución legal se podía alterar por acuerdo de los padres, o resolución judicial fundada en el interés del hijo, en ambos casos para atribuir individualmente al otro padre la patria potestad.

${ }^{14}$ Tanto la regla de atribución legal como la de atribución judicial habían sido objeto de cuestionamientos principalmente relativos a su constitucionalidad; todo esto se encuentra suficientemente documentado en la doctrina nacional por lo que no se hará revisión de ello. Al respecto se pueden revisar las dos principales posiciones en: Rodríguez, M. S., "El cuidado personal de niños y adolescentes en la familia separada: criterios de resolución de conflictos de intereses entre padres e hijos en el nuevo derecho chileno de familia", en Revista Chilena de Derecho, vol. 36, N 3, 2009, pp. 558- 564; y Lathrop, F., "(In)constitucionalidad de la regla de atribución preferente materna del cuidado personal de los hijos del artículo 225 del Código Civil chileno", en Revista Ius et Praxis, año 16, N² 2010, pp. 147-184. Previamente en el mismo sentido de esta última, Barros, E., "Notas Históricas y Comparadas sobre el Nuevo Ordenamiento Legal de Filiación", en Fundación Facultad de Derecho Universidad de Chile, El nuevo estatuto de filiación en el código civil chileno, LOM Ediciones, Santiago, 1998, p. 47-48.

En lo tocante a la atribución judicial que regulaba el art. 225 CC el Tribunal Constitucional acogió parcialmente un requerimiento y lo declaró inaplicable por inconstitucional días antes de la publicación de la Ley 20.680. El Tribunal razona que la excepción que el inc. tercero del art. 225 CC contemplaba para variar la regla de atribución que estuviera operando, resulta excesivamente onerosa y desproporcionada para aquel de los padres que, no teniendo el cuidado personal de los hijos, aspira a tenerlo, pues exige la ocurrencia de circunstancias tan altas y calificadas que constituyen una diferencia de trato que cabe calificar de arbitraria y que no tiene amparo en la Constitución. Sentencia de 30 de mayo de 2013, en autos Rol No 2306-12-INA, consultada en www. tribunalconstitucional.cl. 
Fluye de la norma la estrecha dependencia entre la patria potestad y el cuidado personal de los hijos en los casos de vida separada de los padres: la patria potestad era ejercida por el padre que tenía el cuidado personal del hijo, solución que se justifica en la necesidad de facilitar su ejercicio. Como consecuencia de lo anterior, el ejercicio de la patria potestad siempre era individual y constantemente le correspondía a la madre, ya fuera por la ausencia de acuerdo que otorgara al padre tal cuidado, ya fuera por la dificultad de probar en juicio las circunstancias legales que permitían alterar la atribución legal. Por lo mismo, ella podía tener una relación materno-filial fortalecida no solo porque el cuidado personal ordinario implica la crianza y educación diaria de los hijos -y por tanto una mayor influencia en su formación-, sino también porque la titularidad de dicho cuidado traía como consecuencia la titularidad y ejercicio de la patria potestad, y con ello la representación de los hijos y la administración y derecho legal de goce sobre sus bienes ${ }^{15}$.

Desde otra óptica, la madre solo accedía subsidiariamente a la patria potestad, ya fuera porque en vida conjunta había alcanzado un acuerdo con el padre o porque el juez accedía a su petición cuando ella probaba que el interés del hijo lo hacía indispensable. Su ejercicio siempre subsidiario implicaba una discriminación a favor del padre. Ahora bien, si en vida separada normalmente ejercía la patria potestad, era por la atribución legal del cuidado personal, no porque el legislador hubiera igualado su posición respecto del padre.

En suma, si bien la Ley 19.585 extendió las posibilidades de ejercicio materno de la patria potestad ${ }^{16}$, la ausencia de paridad fue calificada como atentatoria con la igualdad de género ${ }^{17}$. En la realidad práctica, sin embargo, la regla de atribución legal del cuidado personal de los hijos peligrosamente estaba generando una concentración de poderes y facultades en la madre privando al padre prácticamente de todos los efectos esenciales que configuran la relación de filiación ${ }^{18}$. Por ello se ha afirmado que tal regulación no solo violaba el principio del interés superior del niño al sustraer a uno de los padres, sin una causa grave para ello, de casi todas las facultades y derechos de filiación, sino que además infringe los principios de la igualdad ante la ley y de no discriminación ${ }^{19}$.

\subsection{Modificaciones introducidas por la Ley 20.680}

La Ley 20.680 tuvo su origen en dos proyectos refundidos: el primero, correspondiente al Boletín 5917-18 de 2008 ${ }^{20}$, planteaba modificaciones en los arts. 222, 225,

${ }^{15}$ Sobre la base de tal realidad Barcia ha indicado que nuestro Derecho ba desconocido por completo las facultades $y$ derechos del padre no custodio, con la sola excepción de la relación directa y regular y que el sistema chileno incentivó la inbibición de la litigación por parte del padre: Barcia, R., "Hacia un sistema de filiación que consagre facultades y derechos específicos para el padre no custodio", en Revista de Derecho (Valdivia), vol. XXVI, No 2, 2013 pp. 26-28.

${ }^{16}$ Court, E., Nueva Ley de Filiación, editorial Jurídica ConoSur, Santiago 2000, p. 161.

${ }^{17}$ López, G., Nuevo estatuto de la filiación y los derechos esenciales, editorial Jurídica ConoSur, Santiago 2001, p. 190.

${ }^{18}$ Acuña, M., Efectos Jurídicos del divorcio, AbeledoPerrot - Thomson Reuters, Santiago, 2011, p. 385.

19 Barcia, R., "Hacia un sistema de filiación que consagre facultades y derechos específicos para el padre no custodio", en Revista de Derecho (Valdivia), vol. XXVI, No 2, 2013, p. 28.

${ }^{20}$ Boletín 5917-18, ingresado el 12 de junio de 2008, disponible en www.bcn.cl. 
228, 229 y 245 del CC, además del art. 104 de la Ley sobre Tribunales de Familia, en materia de procedencia de la mediación. Para los arts. 225 y 245 CC se proponía, entre otros cambios, que el cuidado personal y el ejercicio de la patria potestad fueran compartidos como regla legal cuando los padres vivían separados, sin perjuicio de admitir acuerdo o resolución judicial diversa. El segundo proyecto, contenido en el Boletín 7007-18 de $2010^{21}$, proponía modificaciones que incidían solo en los arts. 225 y 228 CC: el primero, seguiría el modelo español en materia de cuidado personal, en el que la regla general es el acuerdo de los padres, pudiendo modificarse judicialmente la atribución en virtud del interés superior de los niños; el segundo se derogaría de plano, por contravenir derechos fundamentales que emanan de la naturaleza y la dignidad humana. Ninguno de los proyectos puso énfasis en la situación de la patria potestad y durante la discusión parlamentaria el debate decantó principalmente en temas de cuidado personal y responsabilidad parental. Veamos esquemáticamente cómo han quedado regulados el cuidado personal y la patria potestad:

Si los padres viven juntos, el art. 224 CC mantiene la regla de actuación de consuno, con dos importantes cambios: se elimina la expresión cuidado personal de la crianza y educación, con ello el contenido del cuidado cambia su sentido; y se agrega un criterio de actuación: el principio de corresponsabilidad, en virtud del cual ambos padres, vivan juntos o separados, participarán en forma activa, equitativa y permanente en la crianza y educación de sus hijos ${ }^{22}$.

Si los padres viven separados conforme al nuevo art. 225 CC, pueden determinar de común acuerdo que el cuidado personal de los hijos corresponda a uno de ellos o a ambos en forma compartida. A falta de acuerdo, los hijos continuarán bajo el cuidado personal del padre o madre con quien estén conviviendo. Cuando las circunstancias lo requieran y el interés superior del hijo lo haga conveniente, el juez podrá atribuir el cuidado personal del hijo al otro de los padres, o radicarlo en uno solo de ellos, si por acuerdo existiere ejercicio compartido, todo ello sin perjuicio de lo dispuesto en el art. 226 CC.

Los cambios revelan la voluntad del legislador de dar preeminencia a los progenitores en la organización de la convivencia con los hijos, mediante un acuerdo en que convengan el cuidado individual o un ejercicio compartido. Este acuerdo necesariamente debe contener un pacto acerca de la relación directa y regular del padre o madre que no tenga el cuidado personal, con lo que se asegura el derecho del niño a relacionarse siempre con ambos progenitores ${ }^{23}$. La regla de atribución legal sitúa el cuidado personal de los hijos en aquel de los padres con quien se encuentren conviviendo, sin distinción

${ }^{21}$ Boletín No 7007-18, ingresado a la Cámara el 29 de junio de 2010, disponible en www.bcn.cl.

22 Para el examen del principio de corresponsabilidad parental se puede revisar: Acuña, M., "El principio de corresponsabilidad parental", en Revista de Derecho Universidad Católica del Norte, Año 20, N², 2013, pp. 21-59.

${ }^{23}$ Se trata del derecho del niño a la coparentalidad consagrado internacionalmente en el art. 9 de la CDN. 
de sexo o edad de los hijos, ni de sexo de los padres ${ }^{24}$. Por lo demás, se eliminan las altas exigencias legales para que el juez pueda cambiar al ejerciente del cuidado personal: es suficiente que las circunstancias lo requieran y el interés del hijo lo haga conveniente ${ }^{25}$.

Respecto de la patria potestad la reforma no incide en el contenido, que conserva esencialmente sus atributos típicos; pero sí afecta su titularidad y ejercicio. Si los padres viven juntos será ejercida por el padre o la madre o ambos conjuntamente, según convengan formalmente (inc. $1^{\circ}$ art. 244 CC). A falta de acuerdo, toca al padre y a la madre en conjunto el ejercicio de la patria potestad (inc. $2^{\circ}$ art. 244 CC). Cuando el interés del hijo lo haga indispensable, a petición de uno de los padres, el juez podrá confiar su ejercicio al padre o madre que carecía de él, o radicarlo en uno solo de los padres, si la ejercieren conjuntamente. El cambio es trascendente en términos de igualación de los padres en la relación paterno-filial al sustituir la norma que atribuía al padre el ejercicio exclusivo por una regla de ejercicio conjunto, siguiendo así la lógica del cuidado personal en vida conjunta: ambos padres deben compartir las funciones.

Si los padres viven separados la patria potestad será ejercida por aquel que tenga a su cargo el cuidado personal del hijo, o por ambos, de conformidad al art. $225 \mathrm{CC}$. Con ello se mantiene la dependencia entre ejercicio de la patria potestad y atribución del cuidado personal. Por acuerdo de los padres o resolución judicial fundada en el interés del hijo, puede atribuirse la patria potestad al otro padre o radicarla en uno de ellos si la ejercieren conjuntamente. Además, basándose en igual interés, los padres pueden ejercerla en forma conjunta (art. 245 inc $2^{\circ} \mathrm{CC}$ ). En estas hipótesis también el cambio es significativo, debido a que por primera vez se permite que aun viviendo separados los padres el ejercicio de la patria potestad pueda ser conjunto, tengan o no el cuidado personal compartido de los hijos.

Se ha comentado que la reforma de 2013 incorpora el principio del interés superior del hijo para la determinación judicial del ejerciente de la patria potestad ${ }^{26}$, cuestión que no es tal, por cuanto en este punto no hay variación alguna: se mantienen las indicaciones para que el juez confíe el ejercicio de la patria potestad cuando el interés del hijo lo haga indispensable (art. 244 CC) o la atribuya por resolución judicial fundada en el interés del hijo (art. 245 CC), incorporadas al Código Civil por la Ley 19.585.

\section{Comportamiento actual de la patria potestad y el cuidado personal de los hijos}

Durante la vida conjunta de los padres se produce por vía legal total simultaneidad en la lógica de compartir las responsabilidades y deberes paterno-filiales; el legislador se inclina hacia modelos de ejercicio compartido o conjunto de los deberes y responsabilidad, dando a entender que ambos padres se encuentran igualmente habilitados

\footnotetext{
${ }^{24}$ Se sigue la regla de radicación según convivencia del párrafo final del art. 156 del Código Civil español.

${ }^{25}$ El nuevo art. 225-2 CC provee al juez orientaciones y criterios que permiten que este haga una revisión de los elementos que son centrales para la verificación del interés superior del menor en el caso concreto.

${ }^{26}$ Lepin, C., "Reformas en las relaciones paterno-filiales. análisis de la Ley N ${ }^{\circ} 20.680$ ”, en La semana jurídica, año 2, $\mathrm{N}^{\circ}$ 58, Legalpublishing, 2013, p. 6.
} 
tanto para el cuidado personal como para el ejercicio de la patria potestad; si los padres nada han acordado, ambos deben asumir tales deberes (arts. 224 inc. $1^{\circ}$ y 244 inc. $2^{\circ}$ CC). Es posible disociar tales ejercicios conjuntos solo por acuerdo o resolución judicial.

La regla legal de atribución del ejercicio de la patria potestad en vida separada mantiene su dependencia al cuidado personal, aunque pueden distribuirse tales ejercicios por acuerdo o decisión judicial, lo que puede resultar conveniente por ejemplo cuando la vinculación entre los padres, posterior a la separación, se torna progresivamente conflictiva.

A partir de ahí, las grandes diferencias entre la situación del binomio patria potestadcuidado personal antes y después de la Ley 20.680 están dadas por el mayor equilibrio actual en el ejercicio de ambas funciones, con lo que se pone fin a las discriminaciones por razón de sexo. Esta igualación de posibilidades para asumir las funciones parentales produce a su vez un equilibrio en su poder negociador.

Orrego había sintetizado la evolución normativa en la patria potestad y su relación con el cuidado personal de los hijos hasta la Ley 19.585, en cuatro fases que cito textual: Primero, permanecían separados en su ejercicio cuidado personal y la patria potestad, y esta última no podía ser ejercida por la madre, de manera que a falta del padre, el hijo se emancipaba (desde 1857 a 1934); en una segunda fase se concede también la patria potestad a la madre, a falta del padre, pero manteniéndose desvinculados el cuidado personal y la patria potestad (desde 1934 hasta el año 1989); luego se establece que la madre, en caso de corresponderle el cuidado personal de los hijos, podría pedir que se le otorgue también la patria potestad (entre 1989 y 1999); finalmente, corresponderá la patria potestad, sin necesidad de petición a la justicia, al padre o madre que detente el cuidado personal de los hijos (desde 1999 a la fecha) ${ }^{27}$. Me parece posible afirmar que la Ley 20.680 aporta una nueva y quinta fase en esta evolución, caracterizada por un mayor equilibrio entre ambos padres en el ejercicio del cuidado personal y de la patria potestad y por una ampliación de las situaciones en que es posible el ejercicio conjunto de esta última.

Se conservan, sin embargo, los problemas de certeza jurídica respecto de terceros que deseen contratar respecto de derechos o bienes del hijo. Este problema, que se produce por la falta de formalidades en los casos de atribución legal, se venía observando en la práctica ${ }^{28}$. Con todo, antes de la Ley 20.680 los terceros podían presumir que en la mayoría de los casos la representación legal de los hijos la tendría la madre, pues solo a ella le quedaba automáticamente atribuido el cuidado personal en casos de vida

${ }^{27}$ Orrego, J. A., "Consideraciones en torno al cuidado personal de los menores y su relación con la patria potestad”, en Zúñiga, A. (coord.), Estudios de Derecho Privado, Editorial Jurídica de Chile, Santiago 2011 , p. 168.

${ }^{28}$ Se había reparado que las reglas legales de cuidado personal y patria potestad de padres separados llevaban a los terceros a exigir a la madre acreditar los derechos que la ley le otorgaba preferentemente y ella, enfrentada a tal necesidad, no tenía más remedio que acudir al tribunal para que confirmase lo que la ley señalaba, mediante la denominada tuición declaratoria: Orrego, J. A., "Consideraciones en torno al cuidado personal de los menores y su relación con la patria potestad", en Zúñiga, A. (coord.), Estudios de Derecho Privado, Editorial Jurídica de Chile, Santiago 2011, pp. 145 a 194. También en Rodríguez, M. S., "Una relectura de la patria potestad como función tuitiva sobre la persona y bienes de los hijos", en Revista Ius et Praxis, año 16, $\mathrm{N}^{\circ} 1,2010$, p. 79. 
separada y por ello le correspondía también, en esa mayoría de situaciones, el ejercicio de la patria potestad; cualquier alteración de la regla debía estar formalizada en acuerdo o resolución judicial debidamente subinscritos. Hoy, en mi opinión, este problema de certeza jurídica se agudiza con la norma que señala $A$ falta del acuerdo del inciso primero, los hijos continuarán bajo el cuidado personal del padre o madre con quien estén conviviendo. Los terceros ya no tienen un progenitor respecto de quien inclinarse y no siendo suficiente el certificado de nacimiento del hijo, es muy probable que para asegurar sus intereses, exijan al padre o madre antes de contratar que acrediten la convivencia con el hijo, para ello estos deberán concurrir al tribunal para que certifique mediante resolución dicha circunstancia.

\section{SEgundA PARTE}

\section{Ejercicio conjunto de la patria potestad}

La posibilidad de ejercicio conjunto de la patria potestad fue introducida en nuestro ordenamiento por la Ley 19.585 solo para aquellos casos en que los padres viven juntos y así lo convenían en acto solemne, aunque nada se dijo sobre la forma de llevarla a cabo $^{29}$. Era una modalidad residual ${ }^{30}$. La Ley 20.680 imprime notables cambios al respecto, ampliando las hipótesis en que es posible tal ejercicio y estableciendo la forma de desarrollarlo, aunque, como se verá, las nuevas reglas no afectan a todos los atributos de la patria potestad y, por otro lado, un ejercicio efectivamente conjunto puede verse notablemente disminuido con las distinciones de actos que introduce la reforma.

Previamente al análisis normativo, resulta pertinente tener presente algunas de las cuestiones debatidas en la tramitación parlamentaria respecto del ejercicio de la patria potestad. Como se anticipó líneas atrás, solo el Boletín 5917-18 de 2008 contemplaba modificaciones en materia de patria potestad, al respecto se proponía como primer inc. del art. 245 CC lo siguiente: Si los padres viven separados, la patria potestad será ejercida en primer término por ambos en conformidad con lo previsto en el artículo anterior. El ejecutivo presentó una indicación con la finalidad de que en aquellos casos en que los padres tengan el cuidado personal compartido de sus hijos, la patria potestad también sea compartida y adicionalmente se permita al juez decretar, o a las partes convenir, la patria potestad compartida sin perjuicio que un solo padre tenga el cuidado personal del hijo. Tales indicaciones tenían por objeto, según su propio texto, hacer partícipe al padre no custodio

${ }^{29}$ El proyecto inicial consideraba la presunción de que los actos realizados por uno de los padres cuentan con el consentimiento del otro. Se ha calificado de olvido la no inclusión de tal propuesta en la Ley 19.585, al desconocerse las razones de su exclusión: Court, E., Nueva Ley de Filiación, editorial Jurídica ConoSur, Santiago 2000, p. 162.

${ }^{30}$ Se había advertido que ello atentaba contra el principio de igualdad: Schmidt, C., "De las relaciones parentales conforme al nuevo estatuto filiativo”, en Schmidt, C. y Martinic, M. D. (directoras), Instituciones de derecho de familia, LexisNexis, Santiago, 2004, p. 78. 
en las decisiones trascendentes que involucren a los bijos: la representación judicial y administración de sus bienes. Con esta medida se está fomentando la corresponsabilidad y dando mayores facultades al padre, no obstante por ley sea la madre a quien corresponda el cuidado personal y así dar mayor equilibrio a las potestades de ambos en relación con el bijo ${ }^{31}$. Con ello se ampliaban las propuestas del proyecto, introduciendo cambios en el art. $244 \mathrm{CC}$, en el sentido de alterar la regla supletoria para las situaciones de vida conjunta de los padres.

En el primer informe de la Comisión de Familia ${ }^{32}$ se dejan ver las dos posiciones de los expertos escuchados, por un lado quienes se inclinaban por el ejercicio conjunto, con menores o mayores exigencias ${ }^{33} \mathrm{y}$, por otro, quienes señalaron su desacuerdo a tal posibilidad e insistían en que la patria potestad siguiera radicada en uno de los padres, incluso con los criterios vigentes ${ }^{34}$. El acuerdo adoptado por la Comisión para el art. 244 consistió en reemplazar el inc. $2^{\circ}$ por el siguiente: A falta de la subscripción del acuerdo, toca al padre y madre en conjunto el ejercicio de la patria potestad, y en agregar un nuevo inc. final del siguiente tenor: En el ejercicio de la patria potestad conjunta, se presume que los actos realizados por uno de los padres cuenta con el consentimiento del otro, salvo que la ley disponga algo distinto. Como explica el mismo informe, el objetivo era facilitar el ejercicio conjunto de la patria potestad en el caso que los padres vivan juntos, estableciéndose una presunción simplemente legal en orden a suponer la concurrencia del consentimiento del otro padre, cuando es solo uno el que realiza el acto o contrato. La modificación al art. 245 propuesta en el proyecto de ley fue rechazada sin debate por la Comisión, al tiempo que se aprobó por la unanimidad de sus integrantes las indicaciones parlamentarias y del ejecutivo en cuanto permitían incorporar en el inc. $1^{\circ}$ y $2^{\circ}$ de la disposición la expresión $o$ ambos, posibilitando un ejercicio conjunto en consonancia con lo aprobado en materia de cuidado personal. En el segundo informe de la Comisión se recomendó aprobar las mismas redacciones y propuestas ${ }^{35}$.

La Comisión de Constitución, Legislación y Justicia de la Cámara, en primer trámite constitucional ${ }^{36}$, discutió ampliamente las propuestas de la Comisión de Familia. Respecto de la presunción que se proponía para el inc. final del art. 244 se observó que no estaba exenta de riesgos, pues en la práctica las dificultades que surgen entre los padres que ejercen conjuntamente la patria potestad derivan precisamente de los actos que ejecuta uno solo de ellos ${ }^{37}$; además, si bien contempla la ley recaudos para los efectos de la disposición de los bienes raíces del hijo-como la necesidad de contar con

31 Oficio No01-359 del Ejecutivo que Formula Indicación Sustitutiva, de 30 de marzo de 2011, Boletín 5917-18.

32 Informe de 23 de mayo de 2011.

33 Lathrop señaló que debería regularse más adecuadamente la administración de bienes del hijo, exigiendo a los padres que los gestionaran con la misma diligencia que sus bienes propios y con obligación de rendir cuentas.

${ }^{34}$ Así las profesoras Carmen Domínguez Hidalgo y Carolina Salinas Suárez.

${ }^{35}$ Segundo Informe de la Comisión de Familia de 28 de junio de 2011.

${ }^{36}$ Informe de 11 de enero de 2012.

${ }^{37}$ Opinión de la diputada Turres y de los representantes del Ejecutivo. 
autorización judicial-, no los considera para la enajenación de los bienes muebles, entre estos podía haberlos de valor significativo; conjuntamente con ello, aparecía como un contrasentido autorizar el ejercicio conjunto de la patria potestad y en forma paralela señalar que los actos que uno realice en forma individual se presumen autorizados por el otro ${ }^{38}$. Se pensó que los padres tuvieran de consuno el derecho legal de goce y administración de los bienes del hijo y que si fueren muchos los bienes, podrían dividir la administración por acuerdo o aprobación judicial, permitiendo la actuación indistinta para cumplir funciones de representación legal que no menoscaben los derechos del hijo ni le impusieran obligaciones ${ }^{39}$; sin embargo, se hizo presente la inexistencia de criterios para determinar cuándo habría que entender que los bienes eran muchos ${ }^{40}$. Se hizo notar también que la distinción que parecía necesaria era entre el goce y administración que se debían ejercer conjuntamente, por una parte, y la representación legal, por otra, que podía recaer en padre o madre indistintamente ${ }^{41}$. A partir de ahí se presentó la tercera indicación del siguiente tenor: En el ejercicio de la patria potestad conjunta, los padres podrán actuar indistintamente cuando cumplan funciones de representación legal que no menoscaben los derechos del hijo ni le impongan obligaciones ${ }^{42}$. La discusión se trasladó a determinar si era o no necesario contemplar una norma que permitiera la división de la administración como mecanismo que flexibilizara y simplificara tal gestión ${ }^{43}$. La Cámara aprobó intercalar como inc. $3^{\circ}$ del art. 244 la tercera indicación. Respecto del art. 245 y considerando las propuestas de la Comisión de Familia, las principales cuestiones debatidas giraron en torno a dos temas: la pertinencia de contemplar la posibilidad de ejercicio conjunto de la patria potestad por acuerdo de los padres, aun cuando uno solo de ellos tuviera el cuidado del hijo, con lo que además se seguía la lógica de priorizar el acuerdo de los padres $^{44}$; y hacer aplicable a tal ejercicio conjunto la regla de actuación indistinta de las funciones de representación conforme a la propuesta de redacción del inc. $3^{\circ}$ del art. 244 $\mathrm{CC}^{45}$. Simultáneamente se debatió si era conveniente que el juez también estuviera facultado para atribuir a ambos padres el ejercicio conjunto de la patria potestad ${ }^{46}$, idea que no prosperó por estimarse que no correspondía imponer en contra de la voluntad de los padres tal modalidad en forma coercitiva ${ }^{47}$. Finalmente se aprobó la siguiente redacción: Sin embargo, por acuerdo de los padres o resolución judicial fundada en el interés del bijo, podrá atribuirse la patria potestad al otro padre o radicarla en uno de ellos si la ejercieren

\footnotetext{
38 Opinión del diputado Cristián Monckeberg.

${ }^{39}$ Diputados Turres y Squella.

${ }^{40}$ Objeción del diputado Harboe.

${ }^{41}$ Opinión de los representantes del Ejecutivo.

42 Indicación del diputado Eluchans.

43 Diputados Harboe, Díaz y Squella se plantearon a favor de dicha división; los representantes del Ejecutivo estuvieron por no contemplar dicha posibilidad en la redacción.

${ }^{44}$ A favor diputados Turres y Squella y representantes del Ejecutivo.

${ }^{45}$ Sugerencia de los presentantes del Ejecutivo.

46 Opción defendida por los representantes del Ejecutivo.

${ }^{47}$ Opinión del diputado Eluchans.
} 
conjuntamente. Además, fundado en igual interés, los padres podrán ejercerla en forma conjunta. Se aplicará al acuerdo o a la resolución judicial las normas sobre subinscripción previstas en el artículo precedente, y el siguiente inc. final: En el ejercicio de la patria potestad conjunta, se aplicará lo establecido en el inciso tercero del artículo anterior.

En el Segundo Trámite Constitucional ${ }^{48}$ existió una alta valoración a favor del ejercicio conjunto de la patria potestad como regla supletoria, aun cuando se hizo presente la necesidad de regular con mayor precisión la forma de realizar dicho ejercicio, resultando insuficiente la explicitación que solo se hacía de los actos de representación ${ }^{49}$; entre otras cosas, pues se dejaba de lado la administración de bienes que es también uno de los contenidos de la patria potestad ${ }^{50}$. Durante la discusión en general del proyecto se presentaron indicaciones al inc. $2^{\circ}$ del art. 244 para reemplazarlo por el siguiente: A falta de la suscripción del acuerdo, toca al padre y madre de consuno el ejercicio de la patria potestad, e intercalar el siguiente inc. $3^{\circ}$ En el ejercicio de la patria potestad de consuno, los padres deberán actuar conjuntamente o uno con mandato otorgado por el otro. En caso de que los padres no logren alcanzar un acuerdo respecto a un asunto determinado, el asunto será sometido a la decisión de un mediador elegido de común acuerdo o por resolución judicial ${ }^{51}$. En el segundo informe de la misma Comisión ${ }^{52}$ el texto propuesto para el art. 244 fue observado por diversos motivos y se ideó como solución a los problemas de la actuación conjunta el permitir la actuación indistinta siempre que no perjudique al hijo ni comprometa su patrimonio ${ }^{53}$. Se propuso redactar un inciso señalando que a falta de acuerdo, se entiende que a ambos padres toca el ejercicio de los derechos y deberes de la administración y representación legal de los hijos en común y que, a falta de ley en sentido contrario, el uno actúa con el conocimiento $y$ consentimiento del otro ${ }^{54}$. Un sector observó que otorgar la representación legal a ambos padres podría agravar la situación actual ${ }^{55}$; para salvar eventuales problemas se hizo hincapié en la posibilidad de actuación separada de los padres en aquellas situaciones en que no se comprometiese el patrimonio del hijo ${ }^{56}$, aun cuando la propia legislación en los casos que comprometen tal patrimonio lo protege al exigir autorización judicial ${ }^{57}$. A petición del presidente de la comisión, senador Hernán Larraín, se propuso como nueva redacción para el inc. $3^{\circ}$ del art. 244: En el ejercicio de la patria potestad conjunta, los padres podrán actuar indistintamente cuando no menoscaben los derechos del hijo o cuando cuenten con el consentimiento expreso del otro, sin embargo al discutir sobre ella se prefirió, con algunas adecuaciones, la redacción presentada por la Jefa del Departamento de Reformas Legales

\footnotetext{
${ }^{48}$ Primer Informe de la Comisión de Constitución, Legislación, Justicia y Reglamento de 22 de junio de 2012.

49 Así por ejemplo la profesora Andrea Muñoz.

${ }^{50}$ Opinión de la profesora Fabiola Lathrop.

${ }^{51}$ Informe en Segundo Trámite Constitucional, de 23 de julio de 2012.

52 Informe de 8 de enero de 2013.

53 Sra. Andrea Barros, Jefa del Departamento de Reformas Legales del Servicio Nacional de la Mujer.

${ }^{54}$ Comentarios de la profesora Fabiola Lathrop.

55 Opinión del senador Prokurica.

${ }^{56}$ Sra. Andrea Barros, Jefa del Departamento de Reformas Legales del Servicio Nacional de la Mujer.

57 Opinión de la magistrada Sra. Negroni.
} 
del Servicio Nacional de la Mujer, basada en los planteamientos enviados por la profesora Lathrop que habían contado con alta adhesión ${ }^{58}$, así: En el ejercicio de la patria potestad conjunta, los padres podrán actuar indistintamente en los actos de mera conservación. Respecto del resto de los actos, se requerirá actuación conjunta. En caso de desacuerdo de los padres, o cuando uno de ellos esté ausente o impedido o se negare injustificadamente, se requerirá autorización judicial. La solución fue acordada con el voto favorable de la unanimidad de los miembros presentes de la Comisión. El despacho del nuevo art. 245 CC fue más simple: se hizo aplicable a las hipótesis de ejercicio conjunto en vida separada de los padres la distinción entre actos de mera conservación y el resto de los actos.

Recapitulando, durante la tramitación de la Ley 20.680 existió un amplio consenso en la idea de ampliar las situaciones de ejercicio conjunto, así como en la necesidad de buscar fórmulas que no entorpecieran en demasía tal ejercicio. Para esto se transitó por diversas alternativas: presunción de consentimiento de un cónyuge en los actos realizados por el otro; división de la administración cuando el volumen del patrimonio lo justificara; actuación indistinta para cumplir funciones de representación legal que no menoscaben los derechos del hijo ni le impongan obligaciones; actuación conjunta o de uno con mandato otorgado por el otro; administración y representación legal para ambos padres pudiendo actuar uno con el conocimiento y consentimiento del otro, y finalmente la opción que fue aprobada: actuación indistinta en actos de mera conservación durante el ejercicio conjunto. La discusión giró siempre en torno a dos atributos de la patria potestad: la representación legal de los hijos y la administración de sus bienes.

\section{Hipótesis de ejercicio conjunto de la patria potestad}

A diferencia de lo que ocurre con el cuidado personal, donde solo el acuerdo de los padres que viven separados puede conducir a un ejercicio compartido, en materia de patria potestad no solo se amplían las hipótesis de pacto de ejercicio conjunto, sino que además es la propia ley la que se inclina por dicha modalidad en ciertos casos, quedando solo excluida la posibilidad de su imposición por decisión judicial.

Es posible identificar hoy cuatro supuestos de ejercicio conjunto de la patria potestad: a) cuando los padres viven juntos y así lo acuerdan (art. 244 inc. $1^{\circ} \mathrm{CC}$ ); b) cuando los

${ }^{58}$ La profesora Lathrop había planteado que para establecer reglas prácticas de funcionamiento de la patria potestad cuando esta se ejerce de forma conjunta, se podría optar por una de las dos alternativas existentes en el Derecho comparado: a) Si ambos padres ejercen la patria potestad, a la celebración de los actos jurídicos de representación o administración de los bienes del hijo puede concurrir uno u otro de los padres (actuación indistinta) como regla general, y, de forma excepcional, ambos con su consentimiento expreso (actuación conjunta) en los casos que se requiere autorización judicial; b) Si ambos padres ejercen la patria potestad, podría distinguirse: b.1) Para los actos conservatorios, esto es, actos que no producen alteración del patrimonio, permitir actuación indistinta; b.2) Para los actos no conservatorios, esto es, los que sí van a producir un cambio en el patrimonio del hijo, exigir la actuación conjunta, en cuyo caso ambos padres deben solicitar al juez la autorización para realizar actos en que actualmente la ley exige esta autorización judicial. Lathrop señaló inclinarse por la segunda opción (letra b) porque diferencia entre actos de conservación y de no conservación, lo que genera mayor seguridad a los terceros contratantes. 
padres viven juntos en ausencia de acuerdo por la sola disposición legal (art. 244 inc. $2^{\circ}$ CC); c) por disposición legal consecuencial cuando los padres viven separados y han determinado de común acuerdo que el cuidado personal de los hijos les corresponda a ambos en forma compartida (art. 245 inc. $1^{\circ}$ en relación con el inc. $1^{\circ}$ del art. 225 CC) y; d) cuando los padres viven separados y uno de ellos tiene el cuidado personal, pero basándose en el interés del hijo, ejercen en forma conjunta la patria potestad (art. 245 inc. $2^{\circ} \mathrm{CC}$ ).

Esta ampliación no es menor, pues el ejercicio conjunto de la patria potestad tiene incidencia en una serie de materias que probablemente alcancen ahora mayor notoriedad asi ${ }^{59}$ : a) la responsabilidad en la administración que se extiende hasta la culpa leve (art. 256 CC) y el privilegio de cuarta clase que le confiere el art. $2481 \mathrm{~N}^{\circ} 4$ CC al hijo sobre todos los bienes del padre o madre (deudor), por los créditos generados en la administración de los bienes de los hijos; b) la sanción civil al padre renuente a reconocer a su propio hijo (art. 203 CC), que, como ha precisado la jurisprudencia, no se aplica al padre que durante el juicio expresa tener dudas sobre la paternidad cuya filiación se reclama ${ }^{60}$, que impediría al renuente asumir la patria potestad individual o conjunta, incluso la legalmente establecida; c) el impedimento de segundas nupcias del art. 124 CC; d) la colación en la renta del padre y madre de los frutos que correspondan al ejercicio del derecho legal de goce que no ingresan al activo del patrimonio del hijo, sino que pasan a ser de propiedad del padre y madre por el solo ministerio de la ley desde el momento en que se perciben ${ }^{61}$; se dividirán entre ambos padres por iguales partes si no se ha acordado otra distribución y en esa misma proporción deberán ser incluidos en su declaración de renta por cada uno de ellos ${ }^{62}$.

Los cambios se incardinan en la línea reformista que elimina la atribución de funciones parentales en razón de sexo, promueve los acuerdos de los padres como forma prioritaria de respuesta, no encasilla a priori el interés superior del niño en una solución específica y, asume -como regla- que ambos padres se encuentran igualmente capacitados para el ejercicio de las funciones parentales, vivan juntos o separados. Conjuntamente con ello, el ejercicio conjunto de la patria potestad claramente se orienta a favorecer un

59 Otro aspecto que se actualizó el año 2013 a la realidad social, y aunque en puridad es independiente del ejercicio de la patria potestad, es la legislación sobre las cuentas de ahorro a favor de menores de edad. La Ley 20.679 de 1 de julio de 2013 agregó a la Ley General de Bancos el siguiente nuevo art. 156 bis: Las cuentas de ahorro para menores de edad, ofrecidas por los bancos regidos por esta ley, podrán ser abiertas por el padre o la madre, con independencia de quien tenga la patria potestad del menor de edad, y al art. 35 del DL 2.079, un inc. final del siguiente tenor: Con independencia de quien tenga la patria potestad, la madre también podrá abrir cuentas de aborro a favor de su hijo menor de edad, permitiendo al padre y a la madre, indistintamente, abrir cuentas de ahorro a favor de sus hijos, independiente de quien tenga la patria potestad.

${ }^{60}$ Corte de Apelaciones de Copiapó, 17 de agosto de 2007, en autos rol 230-07, en www. microjuris. com, cita MJJ15471.

${ }^{61}$ Corte Suprema, 13 de marzo de 2012, en autos rol 8761-09, disponible en www.microjuris.com, cita MJJ31167.

${ }^{62}$ Corte Suprema, 13 de marzo de 2012, en autos rol 8761-09, ya citada. Criterio también compartido por el SII, en Circular $n^{\circ} 41$ del 19 de julio del 2007, que imparte instrucciones sobre declaración y pago de los impuestos que correspondan a las rentas generadas por los menores. 
desarrollo real de la corresponsabilidad de los padres en todo ámbito que diga relación con sus hijos, ya no solo en los aspectos personales vinculados con su crianza y educación.

En todos los supuestos de ejercicio conjunto de la patria potestad el juez está facultado para radicarlo en uno solo de los padres. Si los padres viven juntos solo se podrá alterar el ejercicio vigente a petición de uno de ellos cuando el interés del hijo lo haga indispensable (art. 244 inc. $4^{\circ}$ ); cuando viven separados se requiere que la resolución judicial esté fundada en el interés del menor. El matiz de diferencia se justifica porque cuando los padres viven juntos es natural que prime el acuerdo o la disposición legal, que en la mayoría de los casos dará lugar a la situación ideal: ejercicio conjunto. La judicialización no resulta aconsejable para el buen clima familiar, por ello el legislador es más exigente para alterar tal ejercicio cuando los padres viven juntos, no bastando simplemente que el cambio sea conveniente; la radicación individual debe ser indispensable, esto es imprescindible, del todo necesaria, en atención al interés del hijo (art. 244 CC). Para conocer cuál es el interés del hijo en el caso concreto, además de otros antecedentes del proceso, el juez podrá oír al propio menor (art. 16 inc. $2^{\circ}$ Ley 19.968).

\section{3. Ámbito operativo del ejercicio conjunto de la patria potestad}

La patria potestad concede derechos bien precisos a los padres, que conforman lo que tradicionalmente se conoce como su contenido o atributos. El ejercicio de la patria potestad cuando es conjunto se extiende a todos ellos, aunque con distinta intensidad, mermando los alcances de la reforma, por ello resulta relevante detenerse brevemente en el examen de sus principales caracteres:

a) El derecho legal de goce sobre los bienes del hijo, que consiste en la facultad de usar los bienes del bijo y percibir sus frutos, con cargo de conservar la forma y sustancia de dichos bienes y de restituirlos, si no son fungibles; o con cargo de volver igual cantidad y calidad del mismo género, o de pagar su valor, si son fungibles (art. 250, 252 y 260 CC), es un derecho personalísimo e irrenunciable, en cuya virtud el dominio de los frutos se adquiere por el solo ministerio de la ley ${ }^{63}$. El derecho recae sobre todos los bienes del hijo, salvo las excepciones legales, tales como los bienes que integran el peculio profesional o industrial del hijo o los que pertenecen al peculio adventicio extraordinario del art. 250 números 2 y 3 CC. Cuando este derecho corresponde a la madre casada en sociedad conyugal, esta se considera separada parcialmente de bienes respecto de su ejercicio y de lo que en él obtenga, separación que se rige por las normas del art. 150 CC. El derecho legal de goce es el único atributo de la patria potestad que constituye propiamente un derecho, un beneficio como contrapartida a la carga que supone asumir la administración de los bienes del hijo (aun cuando es posible tener la administración y no el derecho legal de goce ${ }^{64}$ ). El

\footnotetext{
${ }^{63}$ Corte Suprema, sentencia de 13 de marzo de 2012, en autos rol 8761-09.

${ }^{64}$ Así se desprende del inc. $2^{\circ}$ del art. 256 CC.
} 
resto de los atributos son más bien deberes o cargas, como precisa la doctrina ${ }^{65}$. Para los casos en que los padres acuerdan o por ley les corresponda el ejercicio conjunto de la patria potestad, el derecho legal de goce puede distribuirse entre ellos de la forma que mejor estimen; a falta de acuerdo el derecho legal de goce se dividirá entre ellos por partes iguales (art. 252 inc. $4^{\circ} \mathrm{CC}$ no modificado por la Ley 20.680).

b) La administración de los bienes de hijo (art. 253 y ss. CC). En términos generales, corresponde a quien ejerza el derecho legal de goce y comprende la gestión normal u ordinaria de dichos bienes en provecho del patrimonio del hijo. Se refiere a los bienes del peculio adventicio ordinario y no a todos los bienes del hijo, pues como expresamente señala el art. 251 CC. El hijo se mirará como mayor de edad para la administración y goce de su peculio profesional o industrial. Puede ser ejercida por uno de los padres o por ambos conjuntamente. La administración de los bienes del hijo puede corresponder a uno o a ambos padres, introduciendo la Ley 20.680 una distinción importante en la forma de desarrollar la administración conjunta.

c) La representación legal de los hijos (art. 260 y ss. CC): en su virtud el hijo actúa en el ámbito judicial o extrajudicial mediante su representante (si es absolutamente incapaz) o bien, representado o autorizado por él (si es relativamente incapaz). En la representación legal del hijo sujeto a patria potestad se altera el efecto normal de la representación en cuanto la actuación del padre o madre obliga al representante (padre o madre) hasta concurrencia del beneficio que este hubiere reportado de los actos o contratos y solo subsidiariamente obliga al hijo representado (art. 261 CC). Este atributo opera con independencia de que el hijo tenga bienes y permite que se actúe por él o se le autorice tanto en el ámbito judicial como extrajudicial; por tanto es posible que el ejercicio de la patria potestad solo se manifieste por la representación legal del hijo sin que existan, en el caso concreto, bienes que administrar y gozar, ya sea porque el hijo no los tiene en absoluto; ya sea porque teniéndolos se trata de bienes excluidos del goce y administración del o los padres conforme al art. 250 CC. En cuanto al ámbito operativo de la representación legal, en doctrina existe bastante aceptación en considerar que su funcionalidad solo es patrimonial. Varas ha precisado con acierto que no se extiende a la representación personal no patrimonial propia de la vida diaria, también denominada extrapatrimonial, existencial o vital ${ }^{66}$.

\footnotetext{
${ }^{65}$ Court, E., Curso de Derecho de Familia. La filiación por naturaleza. Legislación, doctrina y jurisprudencia. AbeledoPerrot, Santiago, 2010, p. 85; Troncoso, H., Derecho de Familia, LexisNexis, Santiago, 2007, p. 327.

66 Varas, J. A., "Decisiones vitales y representación parental: fundamento y límites", en Estudios de Derecho Civil, Familia y Derecho Sucesorio, tomo V, AbeledoPerrot, Santiago 2011, p. 595 y ss. El autor plantea que la representación parental no patrimonial se da por supuesta en la vida jurídica cotidiana y se ejerce de modo completamente natural, aun cuando carece de un tratamiento sistemático, pues está excluida de los efectos personales de la relación paterno-filial. Tal representación no patrimonial comprende la facultad de adoptar decisiones que incumben al menor en su vida, salud, intelecto, emociones, etc. Rodríguez la califica como una función tuitiva no propiamente representativa o sustitutiva de la voluntad del hijo que puede ser sustituida por el juez, y que es además residual, al operar en aquellas materias en
} 
Si bien hasta la tramitación en la Cámara de Diputados el ejercicio de la patria potestad se vinculada claramente con este atributo, ya que la actuación indistinta se restringía a funciones representativas que no menoscabasen los derechos del hijo ni le impusieran obligaciones, la Ley 20.680 se inclinó en definitiva por establecer distinciones según la naturaleza de los actos, pero sin modificar las reglas existentes en el ámbito judicial; en consecuencia: a) en cuanto a la legitimación activa, el hijo no puede comparecer en juicio, como actor contra un tercero, sino autorizado o representado por el padre o la madre que ejerce la patria potestad, o por ambos, si la ejercen de manera conjunta (art. 264 CC); b) en lo que respecta a la legitimación pasiva, en las acciones civiles contra el hijo deberá el actor dirigirse al padre o madre que tenga la patria potestad, para que autorice o represente al hijo en la Litis; si ambos padres ejercen la patria potestad, la ley flexibiliza la regla y permite que la gestión judicial sea válida aun cuando el actor se dirija en contra de uno de ellos (art. 265 CC); c) no será necesaria la intervención paterna o materna -o de ambos en los casos de ejercicio conjunto-, para proceder criminalmente contra el hijo; pero el padre o madre que tiene la patria potestad -o ambos, en su caso- será obligado a suministrarle los auxilios que necesite para su defensa (art. 266 CC). Nuevamente se requiere que ambos participen. En todos estos casos la representación o autorización del padre o madre, o de ambos, puede ser suplida por el juez cuando el o los padres niegan su consentimiento al hijo para la acción civil que quiera intentar contra un tercero, o están inhabilitados para prestarlo (art. 264 inc. $2^{\circ} \mathrm{CC}$ ); o cuando no pudieren o no quisieren prestar su autorización o representación (art. 265 inc. $2^{\circ}$ CC). El juez deberá nombrarle al hijo un curador para la litis, quedando excluida la representación legal.

Revisados los aspectos configuradores básicos de cada atributo de la patria potestad, parece razonable entender que si bien todos ellos admiten un ejercicio conjunto (hoy en un mayor número de situaciones), las reglas referidas a la forma de actuar en tal modalidad incorporadas por la Ley 20.680 se refieren solo a la administración de bienes y a la representación legal ${ }^{67}$. Se desprende también del análisis previo, que en la representación legal las reformas que se introducen están referidas al ámbito extrajudicial, pues no se modifican las normas que regulan el ámbito judicial de la presentación del hijo. A partir de ahí, resulta que el alcance de la reforma, en cuanto a la forma de actuar en un ejercicio conjunto de la patria potestad, es más restringido de lo que pudiera entenderse inicialmente.

\section{Formas de actuación en el ejercicio conjunto de la patria potestad}

Durante la modalidad de ejercicio conjunto de la patria potestad no siempre las actuaciones son realizadas por ambos progenitores, ya sea por la naturaleza del acto, ya sea por la situación en que se encuentra uno o ambos padres.

\footnotetext{
las que el menor de edad no tiene autonomía, sin embargo no queda del todo claro si su posición excluye o no completamente los aspectos personales: Rodríguez, M. S., ponencias: "La representación legal en el ejercicio conjunto de la patria potestad", en las XI Jornadas nacionales de Derecho Civil, Valdivia, 3 al 5 de octubre de 2013.

${ }^{67}$ Así lo evidencia también la historia del establecimiento normativo, según ya fue examinado.
} 
4.1. Situaciones especiales en razón de la naturaleza del acto

Considerando la naturaleza del acto, la Ley 20.680 introdujo la distinción entre actos de mera conservación y el resto de los actos ${ }^{68}$.

- Actos de mera conservación: para estos actos el legislador permite que los padres puedan actuar indistintamente, por lo que resulta interesante determinar cuándo estamos en presencia de actos de mera conservación; qué implica actuar indistintamente y cuál es la finalidad normativa. En términos lingüísticos se trata de actos destinados a mantener algo o cuidar de su permanencia ${ }^{69}$; Claro Solar, tratando de los curadores de bienes, en cuando se distinguen de los curadores generales, particularmente en relación con lo dispuesto en los arts. 487 a 489 CC, alude a actos que no pueden demorarse sin perjuicio para el patrimonio; actos de mantenimiento de los bienes en la forma que el curador los recibe, no pudiendo alterar la forma de los bienes, lo que se justifica por el carácter provisional de estas curadurías ${ }^{70}$; asimismo, durante la discusión parlamentaria se los identificó como aquellos que no producen alteración del patrimonio ${ }^{71}$. A partir de todo ello, debemos entender que los actos de mera conservación que se pueden ejecutar indistintamente vigente en un ejercicio conjunto de la patria potestad son aquellos destinados a mantener los bienes en su estado normal, evitar pérdidas inminentes, menoscabos o disminuciones en su valor. Para reconocerlos normalmente se les atribuyen los caracteres de necesarios y urgentes ${ }^{72}$. Orrego explica que los actos conservativos pueden ser materiales o jurídicos. Es un acto conservativo material, por ejemplo, ejecutar mejoras necesarias en una vivienda; es un acto conservativo jurídico, por ejemplo, interponer una querella posesoria ${ }^{73}$. Actuar indistintamente significa que tanto el padre como la madre, sin distinción ni preferencia, pueden ejecutar el acto meramente conservativo. Resultando necesario y hasta urgente para el bien del patrimonio del hijo, al legislador le resulta indiferente cuál de los dos padres lo ejecuta, con ello al mismo tiempo se ratifica

${ }^{68}$ Se trata de una distinción conceptual que procede del derecho de bienes, por lo que la doctrina ha entendido que supone la existencia de bienes, de ahí que no existiendo tales el ejercicio conjunto siempre será de consuno y no habrá posibilidad de actuar indistintamente. Así también lo entiende Rodríguez, M. S., ponencia "La representación legal en el ejercicio conjunto de la patria potestad", en las XI Jornadas nacionales de Derecho Civil, Valdivia, 3 al 5 de octubre de 2013.

${ }^{69}$ Diccionario de la Real Academia Española.

${ }^{70}$ Claro Solar, L., Explicaciones de Derecho Civil chileno y comparado, De las Personas, vol. II, Editorial Jurídica de Chile, Santiago 1992, p. 210 y ss.

${ }^{71}$ Segundo Informe de la Comisión de Constitución, Legislación, Justicia y Reglamento del Senado, en segundo trámite constitucional de 8 de enero de 2013.

${ }^{72}$ Serrano, R., "La capacidad negocial del menor adulto", en Estudios Socio-Jurídicos, No 9, Bogotá, 2007, p. 172 y Ochoa, O., Personas, Derecho Civil I, ediciones Universidad Andrés Bello, Caracas, 2006, p. 233.

73 Orrego, J. A., "De la Filiación y de la Relación Jurídica entre padres e hijos”, en Apuntes de Derecho de Familia, disponibles en http://www.juanandresorrego.cl/apuntes/derecho-de-familia/, última visita 07 de abril de 2014, p. 49. 
la idea de que padre y madre se encuentran igualmente calificados. La finalidad de esta regla es facilitar la gestión del patrimonio evitando que la administración se entorpezca en exceso al exigir siempre la reunión de ambos padres cuando se trata de actos simples que no suponen obligaciones ni detrimentos en el patrimonio del hijo y cuya no ejecución pronta puede acarrear perjuicios.

- El resto de los actos: respecto de ellos se requiere la actuación conjunta de ambos padres, lo que implica que ambos deben comparecer o autorizar el acto. Pueden presentarse dificultades en la determinación de los actos que integran este grupo originadas en la identificación que suele hacerse entre actos de administración y de conservación ${ }^{74}$. Siguiendo esta línea la expresión el resto de los actos quedaría reservada solo para aquellos que son de disposición ${ }^{75}$, pues los actos de conservación comprenderían a los de administración. En mi opinión, el resto de los actos estaría integrado tanto por actos administrativos propiamente tales como por actos de disposición: los primeros son necesarios para la gestión normal o corriente de un bien o patrimonio, no comprometiendo su valor o estando destinados a incrementarlo, por tanto, a diferencia de los actos de mera conservación, pueden implicar modificaciones en el estado de los bienes. Ciertamente hay puntos de contacto entre los actos de mera conservación y de administración en cuanto ambos se hacen en definitiva en provecho del patrimonio y desde ese punto de vista son necesarios, pero no existe plena identidad pues estos últimos obedecen a la gestión normal y los primeros son de urgente necesidad y por tanto accidentales. Por lo demás, hay que recordar que la ley ha establecido para la generalidad de los actos la actuación conjunta y solo para los de mera conservación la actuación indistinta, por ello sería un contrasentido entender que todo acto de administración es conservatorio y por esa vía intentar excluirlos de la actuación conjunta. Aún es posible un argumento más: el legislador no habla sencillamente de actos de conservación, sino de actos de mera conservación, con lo que se alude, según el sentido natural y obvio de las palabras, a aquellos que solamente, simplemente, sin mezcla de otra $\cos a^{76}$, son de conservación, es decir, solo destinados a mantener y cuidar sin alteración de forma; sin incluir la gestión corriente o administración.

Los actos de disposición, por su parte, pueden implicar una disminución del patrimonio del menor, una enajenación de una parte de él o pueden colocar a un bien en estado de ser perdido (por ejemplo otorgar garantías); en el fondo se trata de negocios que pueden acarrear algún riesgo sobre el patrimonio ${ }^{77}$. Conviene recordar que el ejercicio

${ }^{74}$ Así en León, A., La voluntad y la capacidad en los actos jurídicos, Editorial Jurídica de Chile, Santiago 1991 , p. 23.

${ }^{75}$ Así en Tapia, M. “Comentarios críticos a la reforma del cuidado personal de los hijos (Ley No 20.680)", en Revista Chilena de Derecho Privado, No 21, Santiago 2013, p. 491, y en Lepin, C., "Reforma a las relaciones paternofiliales. Análisis de la Ley No 20.680", en Revista de Derecho-Escuela de Postgrado, N 3, Santiago 2013, p. 300.

${ }^{76}$ Diccionario de la Real Academia Española.

77 Así parece entenderlo también Orrego cuando sin denominarlos señala como el resto de los actos aquellos destinados a incrementar el patrimonio del menor o aquellos mediante los cuales se enajenen bienes 
conjunto de la patria potestad no altera los requisitos y limitaciones para realizar actos de disposición de cierta entidad según lo disponen los arts. 254 y 255 CC.

La finalidad normativa en el ejercicio conjunto de este tipo de actos (de administración y de disposición) es implicar a ambos padres en los asuntos patrimoniales de sus hijos, lo que traerá como resultado que compartan la responsabilidad en actos que pueden alterar la forma del patrimonio del hijo o generar un riesgo a su respecto.

Ahora bien, esta forma de actuación no está exenta de problemas, pues con ella se abren las puertas para que se inicien procesos judiciales con la finalidad de invalidar el acto cuando se ha actuado por uno solo de los padres, debiendo obrar ambos conjuntamente. Sumado a ello, podrían presentarse dificultades de interpretación respecto de actos que se encuentran en la línea limítrofe -algo difusa- entre actos de mera conservación y actos de administración propiamente tal; o entre actos de mera conservación y actos de disposición, sobre todo considerando que ciertos actos de disposición (la venta de un bien, por ejemplo) pueden llegar a considerarse como de mera conservación, según las circunstancias (o viceversa). Para la calificación del acto será determinante evaluar, en el caso concreto, el efecto patrimonial que provoca y la presencia o no del carácter urgente.

\subsection{Situaciones especiales en relación con uno o ambos padres}

Respecto de actos en que es imprescindible la participación de ambos padres y no de aquellos que pueden ser ejecutados indistintamente, puede presentarse:

- Desacuerdo: se produce cuando ambos padres están presentes y se encuentran habilitados para realizar el acto, pero no alcanzan convergencia acerca de la forma de llevar adelante la administración o representación legal. Ambos quieren ejecutar el acto o actuación, manifiestan voluntad, pero no coinciden en los aspectos esenciales para hacerlo.

- Ausencia, impedimento o negativa injustificada de uno: se trata de situaciones donde la voluntad común no puede formarse por razones externas al querer de al menos uno de los padres, ya sea porque el otro no se encuentra en el lugar o estándolo se encuentra imposibilitado de expresar su voluntad, ya sea porque sin causa que lo justifique se opone a la realización del acto. Solo una voluntad se orienta a la realización del acto.

En todos estos casos para que sea posible la realización del acto es necesaria la autorización judicial (art. 244 inc. $3^{\circ}$ y 245 inc. final ambos del CC).

del menor: Orrego, J. A., "De la Filiación y de la Relación Jurídica entre padres e hijos", en Apuntes de Derecho de Familia, disponibles en http://www.juanandresorrego.cl/apuntes/derecho-de-familia/, última visita 7 de abril de 2014, p. 49. Para el autor los actos de enajenación implican una disminución del patrimonio, opinión que no comparto por cuanto la enajenación puede efectuarse a título oneroso y por tanto alterar la composición del patrimonio sin afectar mayormente su valor. También se considera que los actos de disposición implican siempre una disminución del patrimonio en León, A., La voluntad y la capacidad en los actos jurídicos, Editorial Jurídica de Chile, Santiago 1991, p. 23. 


\section{REFLEXIONES FINALES}

La Ley 20.680 ha venido a concretar en nuestro Código Civil algunas de las más importantes tendencias en materia de infancia y familia: el derecho a la coparentalidad de los hijos y la corresponsabilidad de los progenitores; la igualación de géneros en la asunción de los principales deberes parentales (cuidado personal y patria potestad); el desapego legal a los estereotipos en los roles paterno y materno y la comprensión de que ambos padres se encuentran, por regla, igualmente habilitados para ejercer las funciones parentales. Para lograr aquello deroga las reglas de preferencia basadas en el sexo de los padres, da preeminencia a los acuerdos y permite la atribución de las funciones parentales más importantes basados en criterios de concreción del interés superior de los hijos.

Si bien la Ley 20.680 no introdujo una reforma radical al instituto de la patria potestad, ha permitido que esta siga su proceso de evolución hacia un régimen que, por un lado, no discrimina entre los padres al tiempo de definir la titularidad, ampliando las posibilidades y contenido de los pactos, y por otro lado, flexibiliza los sistemas de ejercicio conjunto cuando ello no menoscaba los intereses del hijo.

No obstante, se debe tener presente que si bien se han ampliado notoriamente las hipótesis en que es procedente el ejercicio conjunto, ya no solo por acuerdo de los padres, sino también por disposición legal y vivan aquellos juntos o separados; el alcance de las normas que regulan la forma de llevar adelante tal ejercicio conjunto, posibilitando una actuación indistinta respecto de ciertos actos, no se aplica a todos los atributos de la patria potestad, sino solo en plenitud a la administración de bienes y a la representación legal en el ámbito extrajudicial, como ha quedado demostrado en las líneas que preceden.

\section{BIBLIOGRAFÍA}

Abeliuk, R., La filiación y sus efectos, tomo I, Editorial Jurídica de Chile, Santiago, 2003.

AcuÑa, M., "El principio de corresponsabilidad parental", en Revista de Derecho Universidad Católica del Norte, sección Estudios, Año 20, N² 2, 2013.

Acuña, M., Efectos Jurídicos del divorcio, AbeledoPerrot - Thomson Reuters, Santiago, 2011.

Álvarez, C., "Derechos y obligaciones entre padres e hijos, en particular de la autoridad paterna", en Revista de Derecho Universidad de Concepción, No 204, año LXVI, 1998.

BARCIA, R., "Hacia un sistema de filiación que consagre facultades y derechos específicos para el padre no custodio", en Revista de Derecho (Valdivia), vol. XXVI, N 2, 2013.

Barros, E., "Notas Históricas y Comparadas sobre el Nuevo Ordenamiento Legal de Filiación", en Fundación Facultad de Derecho Universidad de Chile, El nuevo estatuto de filiación en el código civil chileno, LOM Ediciones, Santiago, 1998.

Claro Solar, L., Explicaciones de Derecho Civil chileno y comparado, De las Personas, vol. II, Editorial Jurídica de Chile, Santiago 1992.

Corral, H., "La familia en los 150 años del Código Civil Chileno", en Revista Chilena de Derecho, vol. 32, No 3, 2005.

Court, E., Curso de Derecho de Familia. La filiación por naturaleza. Legislación, doctrina y jurisprudencia. AbeledoPerrot, Santiago, 2010.

Court, E., Nueva Ley de Filiación, editorial Jurídica ConoSur, Santiago 2000. 
Díez-Picazo, L. y Gullón, A., Sistema de Derecho Civil, vol. IV, 10ª edición, Tecnos, Madrid, 2006. Gómez de la Torre, M., Sistema filiativo chileno, Editorial Jurídica de Chile, Santiago, 2007.

Lasarte, C., Principios de Derecho Civil. Derecho de Familia, tomo VI, $7^{\mathrm{a}}$ edición, Marcial Pons, Madrid, 2008.

LATHrop, F., "(In)constitucionalidad de la regla de atribución preferente materna del cuidado personal de los hijos del artículo 225 del Código Civil chileno", en Revista Ius et Praxis, año $16, \mathrm{~N}^{\circ} 2,2010$.

Lathrop, F., "Comentarios a la reforma al Código Civil en materia de efectos de la filiación", en La Semana Jurídica, año II, No 58, LegalPublishing, 2013.

LEón, A., La voluntad y la capacidad en los actos jurídicos, Editorial Jurídica de Chile, Santiago 1991.

Lepin, C., "Reformas en las relaciones paterno-filiales. Análisis de la Ley No 20.680", en La semana jurídica, año 2, No 58, Legalpublishing, 2013.

Lepin, C., "Reforma a las relaciones paterno-filiales. Análisis de la Ley N 20.680 ”, en Revista de Derecho-Escuela de Postgrado, No 3, Santiago, 2013.

López, C., Manual de Derecho de familia y tribunales de familia, tomo I, $4^{a}$ edición, Librotecnia, Santiago, 2007.

López, G., Nuevo estatuto de la filiación y los derechos esenciales, editorial Jurídica ConoSur, Santiago 2001.

Menéndez, J., en Domínguez, A. (coord.), Comentarios al Código Civil, Lex Nova, Valladolid, 2010.

Pérez Álvarez, M., en Martínez de Aguirre, C. (coord.), Curso de Derecho Civil (IV), Derecho de Familia, $3^{\text {a }}$ edición, Colex, Madrid, 2011.

Ochoa, O., Personas, Derecho Civil I, ediciones Universidad Andrés Bello, Caracas, 2006.

OrRego, J. A., "Consideraciones en torno al cuidado personal de los menores y su relación con la patria potestad", en Zúñiga, A. (coord.), Estudios de Derecho Privado, Editorial Jurídica de Chile, Santiago 2011.

Orrego, J. A., "De la Filiación y de la Relación Jurídica entre padres e hijos", en Apuntes de Derecho de Familia, en http://www.juanandresorrego.cl/apuntes/derecho-de-familia/.

Roca, E., en Amoros, M. (coord.), Comentarios a las reformas del Derecho de Familia, vol. I, Tecnos, Madrid, 1984.

Rodríguez, M. S. "Una relectura de la patria potestad como función tuitiva sobre la persona y bienes de los hijos”, en Revista Ius et Praxis, año 16, No 1, 2010.

Rodríguez, M. S., "El cuidado personal de niños y adolescentes en la familia separada: criterios de resolución de conflictos de intereses entre padres e hijos en el nuevo derecho chileno de familia", en Revista Chilena de Derecho, vol. 36, N 3, 2009.

Rodríguez, M. S., ponencia "La representación legal en el ejercicio conjunto de la patria potestad", en las XI Jornadas nacionales de Derecho Civil, Valdivia, 3 al 5 de octubre de 2013.

SCHмidT, C., "De las relaciones parentales conforme al nuevo estatuto filiativo", en Schmidt, C. y Martinic, M. D. (directoras), Instituciones de derecho de familia, LexisNexis, Santiago, 2004.

Serrano, R., "La capacidad negocial del menor adulto", en Estudios Socio-Jurídicos, No 9, Bogotá, 2007.

TAPia, M. "Comentarios críticos a la reforma del cuidado personal de los hijos (Ley No 20.680)", en Revista Chilena de Derecho Privado, No 21, Santiago, 2013.

Troncoso, H., Derecho de Familia, Lexis Nexis, Santiago, 2007.

VARAS, J. A., "Decisiones vitales y representación parental: fundamento y límites", en Estudios de Derecho Civil, Familia y Derecho Sucesorio, tomo V, AbeledoPerrot, Santiago 2011. 
